\title{
Eric E. Smouha and Dennis I. Bojrab: "Cholesteatoma"
}

\author{
Thieme Verlag, ISBN: 978-1-60406-277-9
}

\author{
Flemming Vassbotn
}

Received: 19 February 2012/ Accepted: 20 February 2012/Published online: 8 March 2012

(C) Springer-Verlag 2012

This book is written as a comprehensive manual for cholesteatoma surgery. The authors have been the moderators for several years for the popular course "Surgical decision making in Cholesteatoma" at the annual meeting of the American Academy of Otolaryngology-Head and Neck Surgery. The experience and pedagogical skills of the authors are clearly demonstrated in this project. The scope of the book is meant to be a reference for young surgeons as well as a workbook for more experienced surgeons that have to deal with the various aspects of the disease. The book is pragmatic and clinically comprehensive with discussions and suggestions for surgical problem solving while elegantly steering clear of dogma. The book deserves a subtitle like "surgical techniques and decision making" to show the clinical aspect of the project.

The book is rich in operative photos as well as descriptive artwork to clarify the different surgical topics. The online content further guides the reader through different surgical scenarios. The first chapter introduces the disease, followed by three chapters presenting middle ear, mastoid and meatus surgery. Each chapter has an historical introduction and a basic review of the relevant clinical anatomy and physiology, as well as a reference section. The core of the book is found in chapter 6: Anatomical Issues That arise at Surgery. Here the authors address specific surgical difficulties such as labyrinthine fistula and facial nerve dehiscence. The authors also give a clinical presentation of surgical controversies such as the canal wall up or canal wall down debate. Challenging topics like cholesteatoma recidivism and congenital disease are also dealt with in separate chapters.

The treatment of cholesteatoma has been an enigma for otosurgeons for many years and surely will be challenging also for the years to come. Excellent textbooks with tothe-point discussions and techniques are seldom. This is a brilliant book that will be highly appreciated both by young surgeons learning the field and more experienced clinicians.

F. Vassbotn ( $\square)$

Head and Neck Surgery, Department of Otolaryngology,

Haukeland University Hospital, Bergen, Norway

e-mail: flemming.vassbotn@ @else-bergen.no 